\title{
Study and Analysis of Delay Sensitive and Energy Efficient Routing Approach
}

\author{
Babar Ali ${ }^{*}$, , Tariq Mahmood ${ }^{2}$, Muhammad Ayzed Mirza ${ }^{3}$, Saleemullah Memon ${ }^{4}$ \\ Muhammad Rashid ${ }^{5}$, Ekang Francis Ajebesone ${ }^{6}$ \\ School of Information \& Communication Engineering \\ Beijing University of Post and Telecommunication, Beijing 100876, China ${ }^{1,4,5,6}$ \\ Faculty of Information Technology, Beijing University of Technology, Beijing 100124, China ${ }^{2}$ \\ Division of Science and Technology, The University of Education, Lahore 54000, Pakistan ${ }^{2}$ \\ School of Electronic Engineering, Beijing University of Post and Telecommunication, Beijing 100876, China ${ }^{3}$
}

\begin{abstract}
Wireless Sensing Networks (WSNs) comprised of significant numbers of miniatures and reasonable sensor nodes, which sense data from surrounding and forwarded data toward the base station (BS) via multi-hop fashion through cluster head node (CHN). The random selection of CHN in WSNs is fully based on the nodes residing energy. The node residing energy and network sustainability is hot research issues of the day in WSNs. There are many deficiencies in less energy adaptive clustering hierarchy (LEACH) RP due to the rapid energy usage of ordinary and CHN because of direct communication to the base station. The rapid draining of node energy produces huge numbers of hole in the network causing retransmission of data packet, route update cost, and E2E delay. In this paper, the proposed Delay Sensitive and Energy Efficient (DSEE) Routing Protocol (RP) select CHN considering distance difference and amount of remaining energy of neighboring nodes. In this proposed approach, data fusion technology (DFT) was implemented to solve the problem of data redundancy, but it does not design a specific data fusion algorithm. At last, simulation experiments proved the superiority of the improved protocol LEACH-DSEE and finally, we compare this improved routing protocol with existing protocols by consideration metrics such as node death ratio, data packet delivery ration and node energy consumption.
\end{abstract}

Keywords-Multi-hop (MH); CHN; WSNs; BS; Data Fusion Technology (DFT); LEACH RP; DSEE

\section{INTRODUCTION}

Nowadays efficient routing in WSNs is the hottest challenges of research. WSNs are characterized by the distribution of many miniature and inexpensive nodes in the monitoring area $[1,41]$. WSNs is a collection of static sensing nodes that collects information and send to the BS. BS accumulate data sensed from the special discovering areas by using the main function of WSNs [2, 3]. WSNs are broadly used such that video surveillance, in which the sensor nodes(snodes) work as cameras that send the collected image information or video information to the destination. In the defense field, s-nodes are distributed in enemy areas that transmitted the enemy's related information to the command headquarters [4-6]. The important characteristics of s-nodes are uses of low power consumption for the short transmission range. The key point of the network data collection is, how to convey the collected information from the source nodes to rely on the node and then send to the BS. Nodes mainly undertake the task of collecting data and forwarding routing data. Routing protocol plays a key for the communication of information from the source node to BS. The important work of routing protocols is to select the optimal route for the node for data forwarding toward the base node [7]. In WSNs routing protocol is the primary technology that works under the network layer [8]. The routing protocol of the network layer ensures that s-node has successfully transmitted data toward the base station. It is very important to diminish the consumption of energy and encompass network life. In addition, WSNs are often large-scale application scenarios so design a routing association that can be applied in very long scale WSNs. Finally, applying data fusion technology in routing protocol greatly reduce the data traffic to retain valid data resulted from a reduction in data redundancy. LEACH-RP solves the problems of a planar RP such as more delay, high energy usage [9, 10]. The practical application proves that LEACH RP has a $15 \%$ longer network lifetime than general planar RP [11]. However, LEACH RP still has some shortcomings like as uneven division and per round unstable numbering of the $\mathrm{CHN}$, lack of consideration of residual energy during the assortment of $\mathrm{CHN}$, etc. These shortcomings will increase the energy usage of nodes, also reduce the network period [12]. LEACH RP stipulates that all nodes and the BS communicate directly, so LEACH RP is not a suitable protocol for very large-scale WSNs application [13]. The working of LEACH RP is based on data fusion technology, but its model does not build on specific data fusion algorithm. Aiming at the shortcomings regarding LEACH RP design, we propose a LEACH-DSEE RP which can reduce the consumption of the energy and simulates this improved protocol. All experimental results prove that the LEACH-DSEE RP can proficiently reduce energy consumption as compared with different LEACH, LEACH-M LEACH-C, there have been many improvements based on original LEACH protocol in recent ten years. The most famous improvement RP is LEACH-C RP [14], the main idea of LEACH-C and LEACH-Mobile (M) RP is the choice of the best $\mathrm{CHN}$ set through BS control. For the performance measurement of lossy network \& less power RP algorithm, various mobility models used such as GMM, RWP, MGM [15]. Two important issues in WSNs, as they can directly impact the lifetime of network \& operation, one is sensing coverage and second is the connectivity of network $[39,40]$.

\footnotetext{
* Corresponding Author
} 


\section{RELATED WORK}

Fig. 1 explained the architecture of WSNs. WSNs comprises of many s-nodes, BS, Internet networks and servers. $\mathrm{S}$-nodes are composed of four modules. The function of the sensor module is to collect data for monitoring area; the function of the processor module is to process collected data information, such as data fusion; communication module is responsible for communication; power module is responsible for providing electricity. WSNs establish data communication links from source nodes to destination nodes through selforganization [16-19]. In Fig. 1, five labeled nodes (ABCDE) form a data transmission path from the source node (Node A) to the final node (BS). BS forwards collected data to the offshore network station. WSNs is dissimilar from the traditional WSNs. There are many data collection protocols in WSNs [20-22]. LEACH is a low-energy adaptive layered routing protocol. Later, many-layered RP has enhanced behalf on the LEACH RP. The operation of LEACH RP [23-25] is periodic. Flooding protocol is a classic planar RP for cluster building and data collection. Its advantage is that it does not need to maintain routing information. All collected data from the source nodes are forwards to all neighbor nodes and the neighbor node forwards its own information and collected information to the next coming nodes until the end node receives the data. The PED\&P (Power Efficient Data Gathering \& Aggregation) in WSNs protocol systematizes the nodes in the whole system into a least spanning tree based on the BS which diminishes the consumption of energy in the whole system [26, 27].

LEACH-C RP [28] is a very famous LEACH improvement protocol. At the beginning of each round, it is controlled by the $\mathrm{BS}$, which choose the optimal $\mathrm{CHN}$ set depending on the node's residual energy and location information. LEACH-C is different from the LEACH RP in clustering stage. The nodes of LEACH-C RP have the information about their location, all other non-CHN calculate their nearest $\mathrm{CHN}$ behalf on the location information of the CHN broadcasted by the BS and join its cluster. Literature [29] proposes an enhanced protocol based on LEACH protocol. The improved protocol also runs repeatedly in the unit of "wheel". One round is alienated into cluster building and data the collection stages. The improved protocol improves the threshold $\mathrm{T}_{\mathrm{n}}$ formula.

$\mathrm{T}_{\mathrm{n}}=\left\{\begin{array}{c}\frac{\operatorname{Probability}(\mathrm{p})}{1-\mathrm{p} \times\left[\operatorname{rmod}\left(\frac{1}{\mathrm{n}}\right)\right]} \times\left(\mathrm{mE}_{\mathrm{p}}(i)+\mathrm{nN}(i)\right) \\ 0\end{array}\right.$

Ep $(i)$ is nodes energy factor and If node $I$ have a large amount of residual energy, $\operatorname{Ep}(i)$ is also large. The density factor of node $\mathrm{N}(i)$ and $\mathrm{m}, \mathrm{n}$ are weight parameters, and $0<\mathrm{m}$, $\mathrm{n}<1$, and $\mathrm{m}+\mathrm{n}=1$. Document [29] also improves the threshold Tn formula. The new threshold Tn considers the node residual energy factor $\&$ node distance factor from BS.

$\mathrm{T}_{\mathrm{n}}=\left\{\frac{\text { Nodes probability }\left(\mathrm{p}_{\mathrm{n}}\right)}{1-\mathrm{p}_{\mathrm{n}} \times\left[\mathrm{r} \bmod \left(\frac{1}{\mathrm{p}_{\mathrm{n}}}\right)\right]} \times\left(1+\mathrm{m} \times \mathrm{k} \times\left(\frac{\mathrm{E}_{\text {current }}}{\mathrm{E}_{\text {total }}}\right)\right)\right\}$
$+\mathrm{n} \times \mathrm{d}_{2}^{2} /\left(\mathrm{d}_{1}^{4}+\mathrm{d}_{2}^{2}\right)$
0
In equation (2), $m$ and $n$ are weight parameters and $m+n$ $=1$. $\mathrm{K}$ is the expected number of $\mathrm{CHN}$, residual energy $\mathrm{Ec}_{\text {urrent }} / \mathrm{E}_{\text {total }}$ ratio is $\mathrm{b} / \mathrm{w}$ the current and all nodes, $\mathrm{d}_{2}$ is the distance $\mathrm{b} / \mathrm{w}$ the monitoring area center and node, $\mathrm{d}_{1}$ is the distance $\mathrm{b} / \mathrm{w}$ the node $\&$ BS. The improved protocol proposed in reference [30] deliberates the residual energy \& distance from the $\mathrm{BS}$ during the selection of $\mathrm{CH}$ nodes. In literature [31, 32], new sort of hierarchical protocol was anticipated behalf on LEACH-C \& original LEACH protocols. The proposed protocol attains energy proficiency through variation cluster heads selection formula which has huge energy and contribution of short role in the selection of $\mathrm{CH} / \mathrm{VCH}$ and the steady-state (SS) phase. The introduction of $\mathrm{VCH}$ introduce the frequency of re-clustering poorer and extends the lifetime in the SS phase. The fertile way to make WSN more energy efficient is to split the network into the various cluster. In clustered networks, the ordinary node senses information from the environment and transmit it to $\mathrm{CHN}$. The $\mathrm{CHN}$ gathering the sense data and perform the aggregation on collected data before sending to the BS to achieve the scalability, load balancing, data fusion, and reduction of e2e delay. The literation [33-35] explain the detailed survey of clustering techniques along with their characteristics and clustering algorithms. Literature [36-39] represents a solar CHN selection based on Solar-aware LEACH (sLEACH). The sLEACH protocol requires some sensor nodes that can convert solar energy into electrical energy and can increase their residual energy through the sun's irradiation. In the sLEACH protocol, Probability of solar node becoming $\mathrm{CHN}$ is increased and the life of the network is prolonged by solar energy. Because the sLEACH protocol adds solar energy to sensor nodes, it is more effective than the generally improved protocol in extending network life duration.

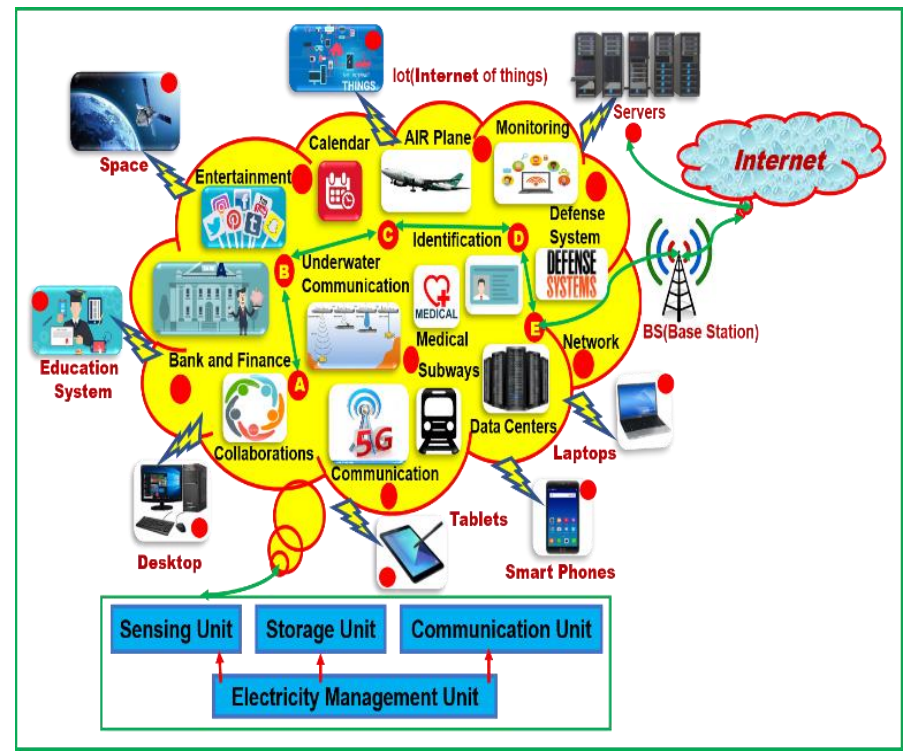

Fig. 1. The Architecture of WSNs. 


\section{PROBLEM DESCRIPTION}

The key inefficiencies of LEACH RP are the following:

- During the selection of CHN, LEACH RP does not deliberate the residual energy. If the amount of residual energy is relatively small, nodes acting as CHN \& can represent to some premature dead nodes.

- LEACH RP does not require the number and distribution of CHN per round, which may cause clusters are unstable and the distribution is not uniform that resulting in maximal and minimal clusters.

- LEACH RP does not deliberate the distance b/w the CHN \& BS. The longer the communication distance between sensor nodes, the more energy usage. So, the nodes far away from the BS may die prematurely.

- LEACH RP requires all CHN to communicate directly with the BS instead of the communication between sensor nodes. If the transmission distance is long, the data information cannot be sent and consume a lot of energy. Therefore, the LEACH RP is not appropriate for huge-range networks.

- LEACH RP requires a CHN to fuse data collected by cluster, but it is not designed specific data fusion algorithm.

\section{Architecture of Proposed Protocol LEACH- DSEE}

This proposed approach mainly related to the reactive networks according to the needs of time depending on applications. It describes the problem of heavy energy usage during data forwarding and selection of $\mathrm{CH}$ Nodes. LEACH DSEE RP provides stable energy consumption by using direct communication between the CHN and BS.

\section{A. Regional Clustering}

The BS logically distributes the monitoring area into numerous small areas, each of which merges clusters according to the strength of nodes involved. If the number of sensor nodes in a small area is not less than threshold $\mathrm{M}$, the small area is a cluster. If the number of nodes in a small area is less than threshold $\mathrm{M}$, it merges with the surrounding small area until the number of nodes in the merged area is less than M, and the merged area becomes a cluster. Fig. 2 explained, all snodes are deployed randomly and uniformly in the experimental area. The matrix box is representing the area to be detected and the black dot is the s-node.

The specific number of small areas is determined according to the actual situation. The proposed scheme BS takes nine small areas that label each small area seen in Fig. 3. Finally, the BS divides clusters according to the number of nodes contained in each small area. BS receives the information consist of the node's location of all sensor nodes that calculates the strength of nodes contained in each small area. If the merged area is less than threshold $\mathrm{M}$, it continues to be merging the surrounding area till not less than the value of threshold M. In the proposed techniques, threshold $\mathrm{M}$ set on half of the average value.

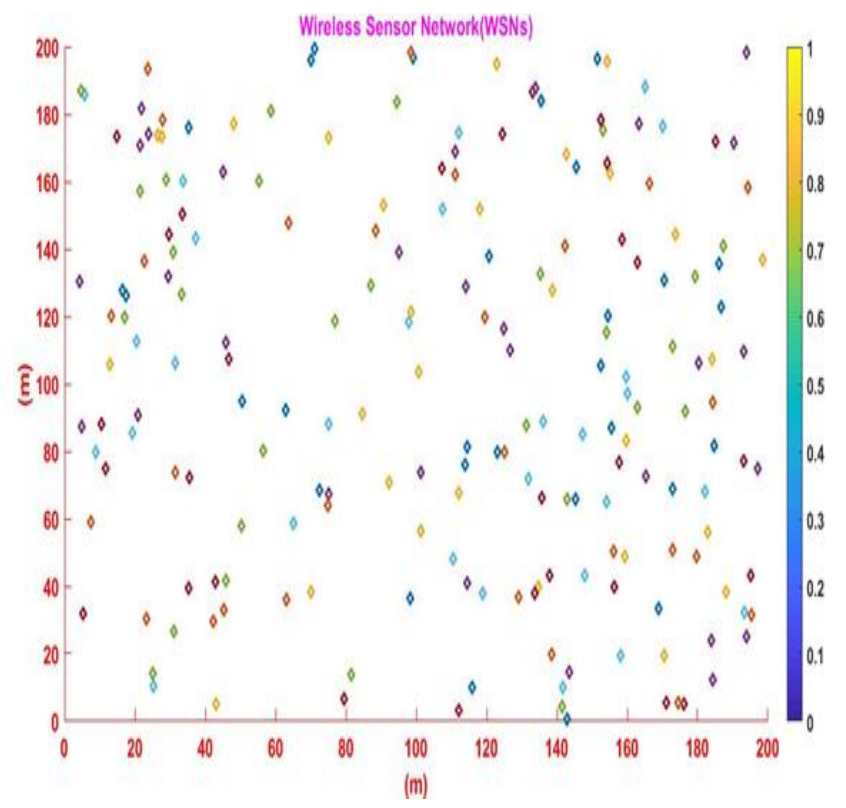

Fig. 2. Deployment of s-Nodes in Monitored Area.

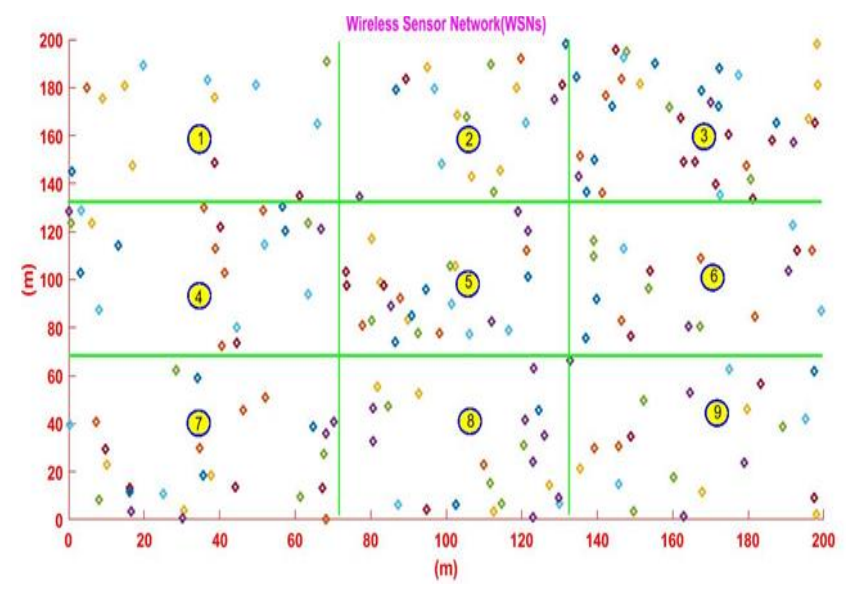

Fig. 3. Division of Monitoring Area.

\section{B. Cluster Head Selection (CHS)}

BS divides the monitoring area into several clusters according to the idea of regional clustering. At the starting of every round, every cluster chooses the $\mathrm{CHN}$ according to the largest amount of residual energy. We see this CHS in Fig. 4.

\section{Inter-Cluster Transmission (ICT)}

The proposed LEACH-DSEE routing protocol, solve the energy consumption issues of network nodes. CHN and BS transmit data through multi-hop and single hop fashion during communication. The nodes are alienated into three categories like nearest node, next nearest nodes, and a farther node according to the distance difference $\mathrm{b} / \mathrm{w}$ the sensor and BS. The nearest $\mathrm{CHN}$ communicates directly to the destination/BS and also work as a relay node. The distant CHN also transmits data directly to the destination/BS and did not work as a relay node. Table I elaborate on the data structures of Cluster-headnode and Cluster Node of LEACH-DSEE. 


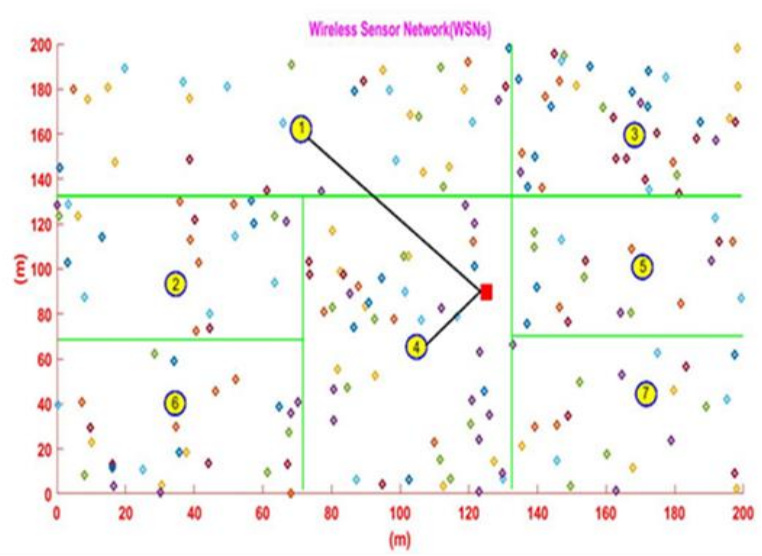

Fig. 4. Cluster Diagram of the Monitored Area.

TABLE I. ELEMENTS OF CHN AND CN

\begin{tabular}{|l|l|}
\hline Name of Elements of CHN and CN & Initial Value \\
\hline Node ID Number & Each Node has a Unique ID \\
\hline Cluster Node & 0 \\
\hline Residual Energy & 1 \\
\hline Dead Node & 0 \\
\hline Location of CHN Position & Each Node has its own Location \\
\hline Cluster Number & 0 \\
\hline $\begin{array}{l}\text { CN Classification Based on Distance } \\
\text { from BS }\end{array}$ & 0 \\
\hline
\end{tabular}

\section{Re-Selection of CHN in Clusters}

In the data collection phase, all cluster members send data information to CHN along with own residual energy and ID information. CHN retain the residual energy information of all its own cluster member nodes. After data collection, CHN utilizes a large amount of energy and Cluster-head-node need to select new CHN. The CHN broadcasts the ID information of the node having a large amount of residual energy in the cluster for the choice of new CHN. All cluster members send the "join cluster" message to the new CHN. Then the new CHN allocates channels to all cluster members and then continues to receive data collection stage.

\section{AlgORITHM FOR THE SELECTION OF OPTIMAL FORWARDED NODES}

Fig. 5 elaborate the routing decision based on residual energy. The $\mathrm{CHN}$ which is close to the BS sends the data directly to the BS and acts as the relay node. The distant CHN also communicate directly to the destination and did not work as a relay node.

\section{PRotocol SimUlation AND Verification}

This section is discussing the simulation environment, experiments nature, dataset, performance parametric and detail results. The experiment in this paper is simulated and verified with the MATLAB tool 2018b, it can handle one-dimensional, two-dimensional and multi-dimensional arrays well and display them graphically [33-36]. This paper uses the powerful graphics processing function of MATLAB to verify the superiority of LEACH-CR protocol in energy consumption. In this research paper, we discuss the LEACH-DSEE, LEACH \& LEACH-C \& LEACH-M are simulated and validated by using MATLAB 2081b tools, and the performance of the four protocols is analyzed and compared by means of the graphical display. The 200 sensor nodes are erratically distributed in the monitoring area of two hundred by two hundred meters and the BS is far away from the monitoring area. The experiment time duration or number of rounds $1600 \mathrm{sec}$.

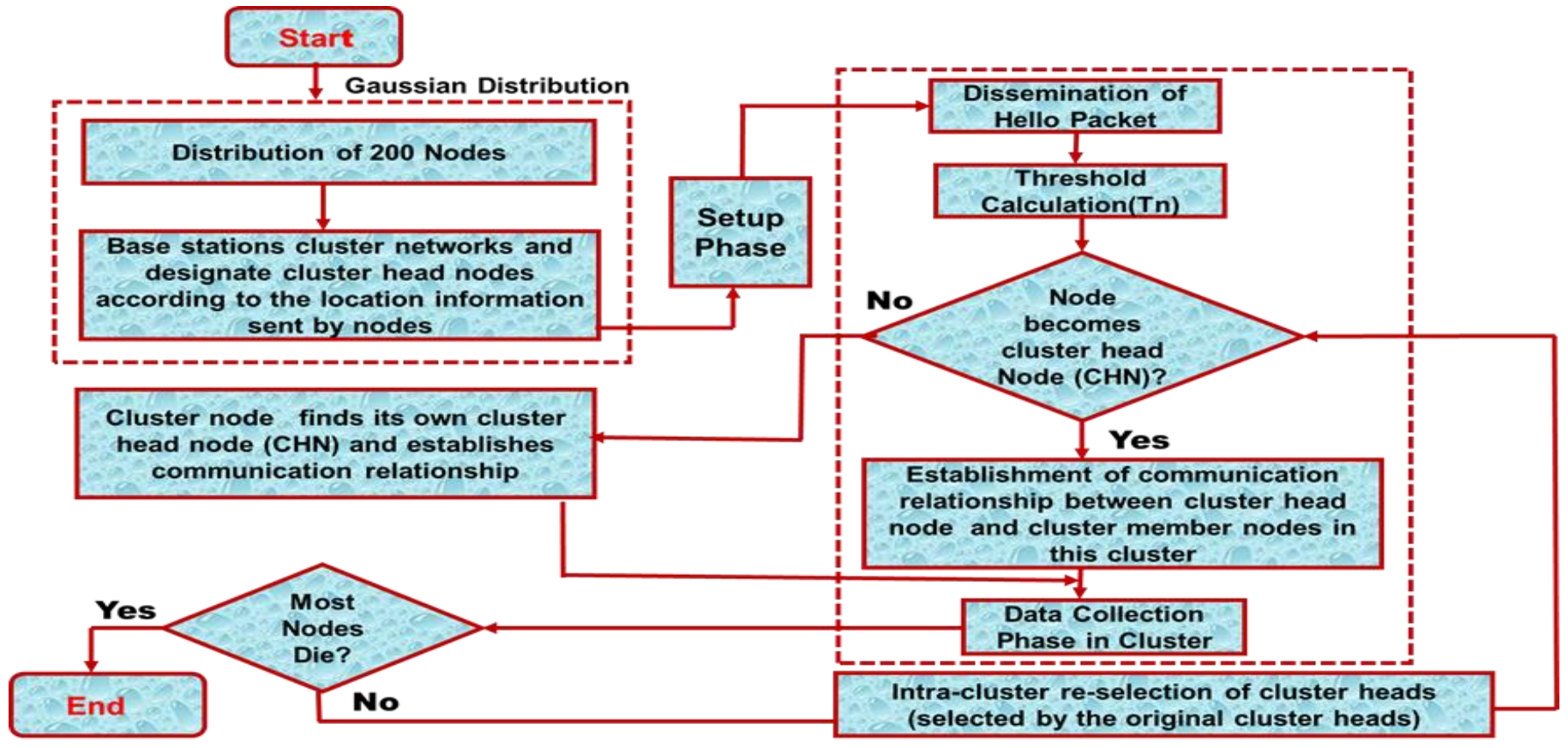

Fig. 5. Algorithm for the Selection of Optimal CHN. 


\section{A. Function Definition}

In the simulation experiments of LEACH-DSEE, LEACH and LEACH-C and LEACH-M, many functions are defined. They work together to establish the network topology and data collection using LEACH-DSEE, LEACH and LEACH-C \& LEACH-M protocols. The important functions in the simulation code are as follows:

1) Init (): Initialize all sensor nodes of the protocol, including location information, initial energy, and common member nodes.

2) Build cluster (): Network clustering. The clustering processes of LEACH, LEACH-DSEE, and LEACH-C \& LEACH-M protocols are different from each other.

3) Gather data (): Data collection. The node collects data and transmits it to BS. Cluster node transmits the collected data directly to the $\mathrm{CHN}$, which fuses the collected data and sends it to the B.S.

\section{B. Simulation Environment}

In equation $3, \mathrm{~d}$ is the distance difference $\mathrm{b} / \mathrm{w}$ source and BS. When $d$ is smaller than threshold $d_{0}$, the communication model of the node is free space channel.

$\mathrm{E}_{\mathrm{tx}}(\mathrm{d}, \mathrm{k})=\left\{\begin{array}{cc}K \times E_{\text {elec }}+k \times \varepsilon_{f s} \times d^{2} & \mathrm{~d}<\mathrm{d}_{0} \\ K \times E_{\text {elec }}+k \times \varepsilon_{\text {amp }} \times d^{4} & \mathrm{~d} \geq \mathrm{d}_{0}\end{array}\right.$

When $\mathrm{d}$ is not less than the threshold $\mathrm{d}_{0}$, the multi-channel attenuation model is adopted. The consumption of energy in snodes for receiving data (kbit) in Equation (4).

$$
E_{r x}(k)=k \times E_{\text {elec }}
$$

In equation (3) and (4), $E_{\text {elec }}$ is the consumption loss parameter of the circuit, and the coefficients of the free space $\left(\varepsilon_{\mathrm{fs}}\right)$ channel and $\varepsilon_{\mathrm{amp}}$ multiple channel attenuation model are and, respectively. The parameters of the experimental environment are as follows (Table II):

TABLE II. ENVIRONMENTAL PARAMETERS OF A SIMULATION EXPERIMENT

\begin{tabular}{|l|l|}
\hline Parameter term & Parameter values \\
\hline Total number of nodes & 200 Individual \\
\hline Monitoring regional scope & $250 \mathrm{~m} \times 250 \mathrm{~m}$ \\
\hline Base station location & $(250,500)$ \\
\hline Packet size & 4000 bits \\
\hline Controlling package size & 100 bits \\
\hline The initial energy of nodes & $0.5 \mathrm{~J}$ \\
\hline Energy usage of DF (nJ/bits)/message & 5 \\
\hline E $_{\text {lec }}$ & 50 \\
\hline$\varepsilon_{\mathrm{fs}}$ & 10 \\
\hline$\varepsilon_{\text {amp }}$ & 0.013 \\
\hline $\mathrm{d}_{\mathbf{0}}$ & $87 \mathrm{~m}$ \\
\hline $\begin{array}{l}\text { LEACH-DSEE Protocol Partition Supervision } \\
\text { Block Number of Measured Areas }\end{array}$ & 9 Block \\
\hline LEACH-DSEE protocol Threshold M \&Rounds & 10 individuals \\
\hline
\end{tabular}

\section{Performance Assessment}

The performance assessment of an RP is based on the number of dead rounds of 1 st the whole network. If the later the node starts to die, the more concentrated the time of node death, the better the performance of this protocol. If the amount of residual energy of a node is zero, then the node is measured as dead. If the strength of the dead node in the network is more than $85 \%$ of the total strength of nodes, the network considered as dead. Therefore, this study uses the number of dead rounds of the first node and $85 \%$ of the nodes in the whole network to judge the performance of a routing protocol [34, 40].

The simulation results of four RP LEACH-DSEE, LEACH and LEACH-C and M show that LEACH-DSEERP is superior to the other four in terms of network lifetime and residual energy. Fig. 6 is representing the simulation of the changes of alive nodes in LEACH-DSEE RP, LEACH RP \& LEACH-C and $\mathrm{LEACH}-\mathrm{M}$ with the increase of running rounds Energy comparison. Fig. 6(a) shows that the Maximum alive node in various LEACH after the 1600 rounds. It can be concluded that LEACH-DSEE RP is superior to LEACH \&LEACH-C and LEACH-M RP because deaths rate is very low. Fig. 6(b) is a comparison of the total network energy remain in LEACHDSEE RP as compare to the LEACH and LEACH-C and LEACH-M protocols. As can be seen from Fig. 6(b), the total remained energy in LEACH-DSEE RP network nodes is much higher than as compare to LEACH and LEACH-C and LEACH-M protocols with the increase of running rounds. Therefore, LEACH-DSEE RP is superior to LEACH and LEACH-C and LEACH-M RP in terms of network lifetime and residual energy. This is of $\mathrm{CHN}$ more uniform through the method of regional clustering Secondly, in LEACH-DSEE, each cluster chooses the node with the largest residual energy as $\mathrm{CHN}$, which balance the network energy consumption and avoids the premature death of the node with little residual energy because it acts as the CHN. Finally, the CHN away from the BS sends data to the BS by multi-hop method which solves the problem of excessive energy consumption. The proposed LEACH-DSEE introduces connectivity facility among the sensing nodes, therefore $\mathrm{CHN}$ requires low consumption of energy to communicate with family nodes, which results in maximum strength of remained alive nodes. Fig. 6(b) showing the remained energy versus rounds and 200 nodes. This result shows the maximum remain energy in LEACH-DSEE as compare to another leach RP.

Fig. 7(a) shows the ratio of packet delivery between the strength of node and during the packet delivery height ratio provide our algorithm LEACH-DSEE RP. Fig. 7(b) shows the energy spectrum during the transmission.

\section{Comparison of LEACH-DSEE RP with LEACH, LEACH- $M$ \&LEACH-C RP}

Table III is representing a comparison between LEACHDSEE routing protocol with the other four LEACH protocol. LEACH-DSEE RP mainly improves around CHN. When choosing $\mathrm{CH}$, residual energy, the distance between $\mathrm{CH}$ and the BS, distribution, and number of $\mathrm{CH}$ are considered. However, neither protocol can be applied to large-scale WSNs networks. The study the LEACH Protocol Improvement for very large-scale WSNs network applications. 


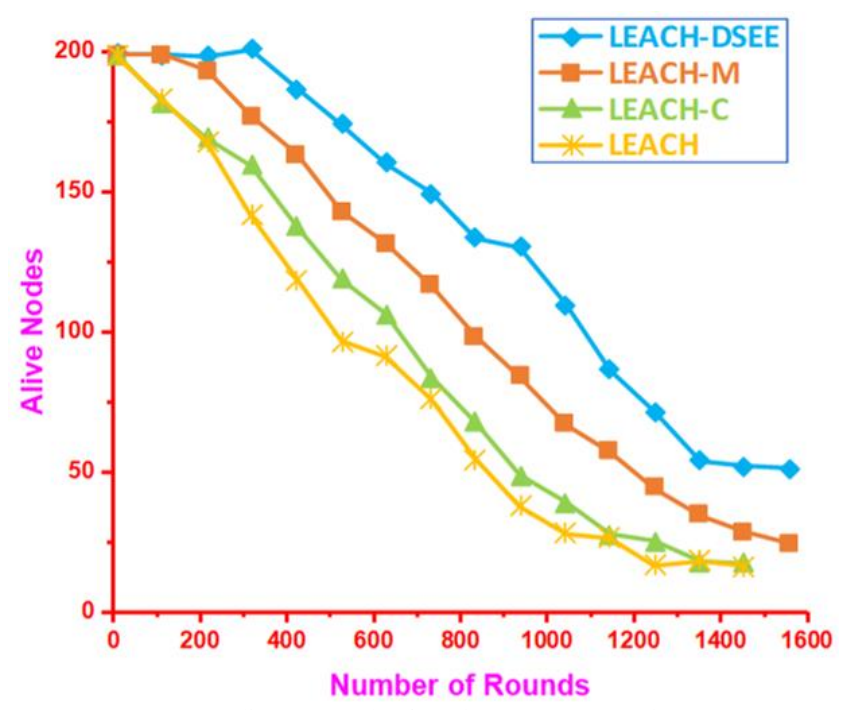

(a) Alive Strength of Nodes Versus Round.

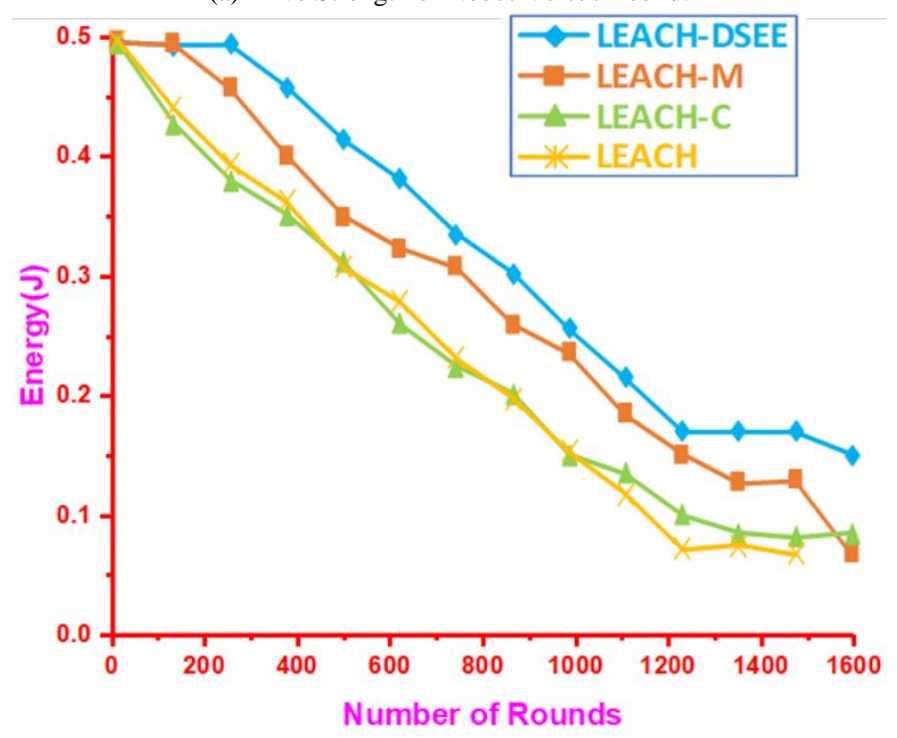

Fig. 6. (b) Energy Comparison.

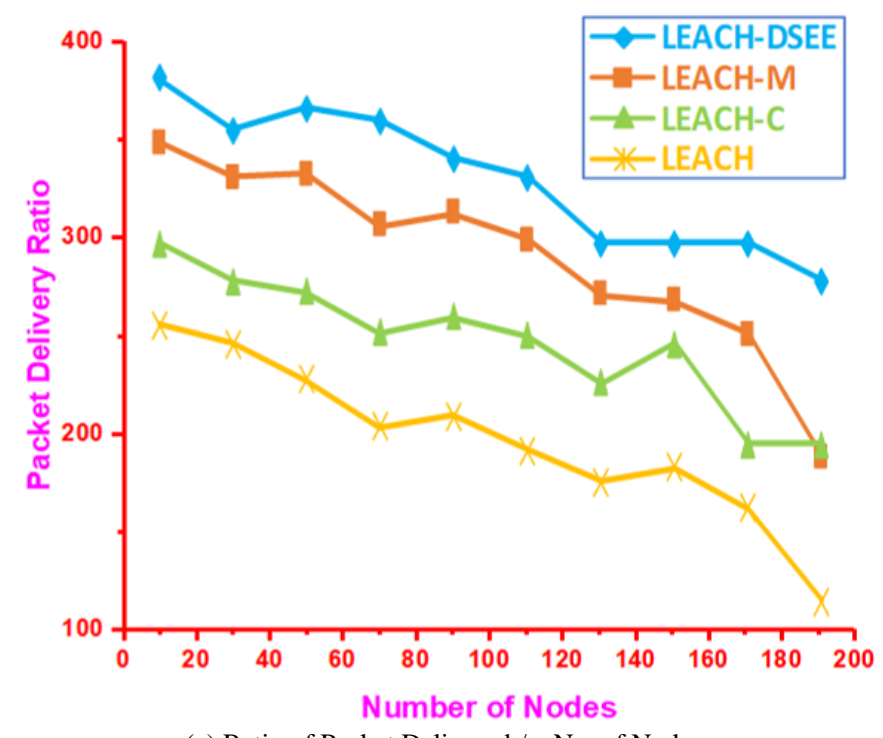

(a) Ratio of Packet Delivery b/w No. of Nodes.

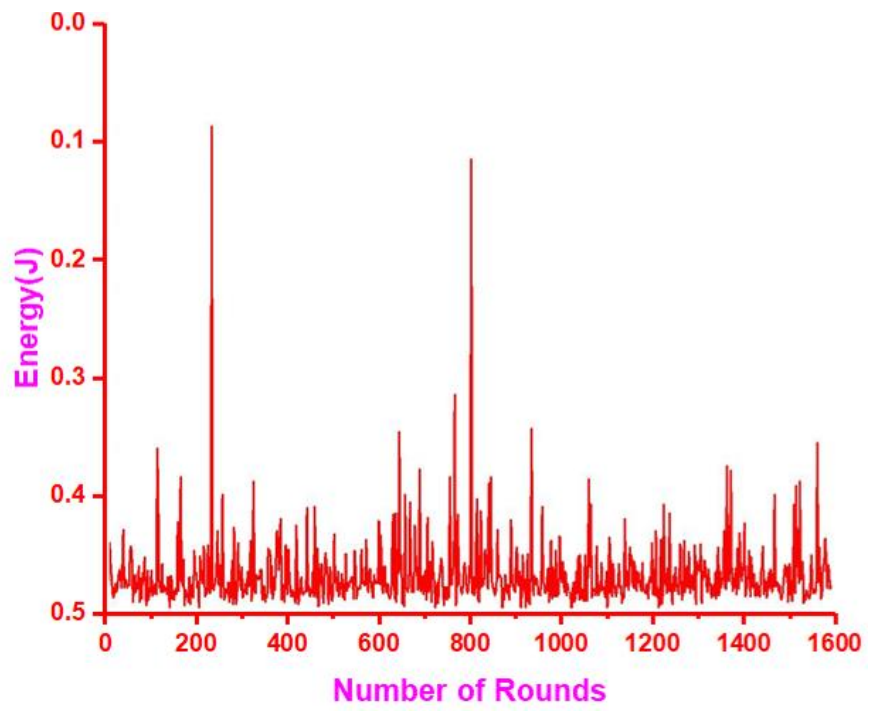

Fig. 7. (b) Energy use Spectrum during the Transmission.

TABLE III. COMPARISON OF LEACH-DSEE RP WITH LEACH, LEACHM \&LEACH-C RP

\begin{tabular}{|l|l|l|l|l|}
\hline & $\begin{array}{l}\text { Whether to } \\
\text { Consider } \\
\text { Clusters } \\
\text { Remaining of } \\
\text { HN Residual } \\
\text { energy }\end{array}$ & $\begin{array}{l}\text { Whether } \\
\text { to Solve } \\
\text { CHN } \\
\text { Distance } \\
\text { from BS } \\
\text { Problem }\end{array}$ & $\begin{array}{l}\text { Whether to } \\
\text { Consider } \\
\text { CH } \\
\text { Distribution } \\
\text { of nodes } \\
\text { and } \\
\text { Number }\end{array}$ & $\begin{array}{l}\text { Can it be } \\
\text { applied? On } \\
\text { a Very-large- } \\
\text { scale } \\
\text { Network Luo } \\
\text { Li }\end{array}$ \\
\hline $\begin{array}{l}\text { LEACH, } \\
\text { LEACH-M } \\
\text { LEACH-C } \\
\text { RP } \\
\text { Agreement }\end{array}$ & No & No & No & No \\
\hline $\begin{array}{l}\text { LEACH- } \\
\text { DSEE } \\
\text { Agreement }\end{array}$ & Yes & Yes & Yes & Yes \\
\hline
\end{tabular}

\section{CONCLUSION}

As a classical hierarchical routing protocol, LEACH solves the shortcomings of a planar routing protocol such as high energy consumption and long delay. But the LEACH protocol not suitable for very large-scale WSNs. The LEACH- DSEE protocol establishes several data communication links to the BS through the CHN layer, so the LEACH- DSEE protocol can be used in very large-scale wireless sensor networks. Experiments results of MATLAB 2018b tools show that LEACH-DSEE protocol can greatly improve the life cycle of wireless sensor networks and reduce the energy consumption of sensor networks. In the proposed scheme, the selection of $\mathrm{CHN}$ is based remained energy \& probabilistic connectivity between family nodes. The improved choice of $\mathrm{CHN}$ increases remaining energy of sensing nodes and increase network lifetime.

\section{ACKNOWLEDGMENT}

This Research work is done by the Chinese Government scholarship student of Master of Electronics and communication. 


\section{REFERENCES}

[1] Rahman, K. C. (2010). A survey on sensor network. Journal of Computer and Information Technology, 1(1), 76-87.

[2] Limin, S., Jianzhong, L., Yu, C., \& Hongsong, Z. (2005). Wireless sensor networks. Beijing: Tsinghua University Press, 5, 7-8.

[3] Cui, L., Ju, H., \& Miao, Y. (2005). Research progress of wireless sensor network. Journal of Computer Research and Development., 42(1), 163174.

[4] Liu, J., Bic, L., Gong, H., \& Zhan, S. (2016). Data collection for mobile crowdsensing in the presence of selfishness. Eurasip Journal on Wireless Communications \& Networking, 2016(1), 82.

[5] Heinzelman, W. R., Chandrakasan, A., \& Balakrishnan, H. (2000, January). Energy-efficient communication protocol for wireless microsensor networks. In Proceedings of the 33rd annual Hawaii international conference on system sciences (pp. 10-pp). IEEE.

[6] Yang, H., Zhou, L., He, K., Deng, C., Zhao, X., \& Qiu, Z. (2010, July). A probabilistic QoS model-checking for the dynamic routing protocol. In 2010 10th International Conference on Quality Software (pp. 441448). IEEE.

[7] Nacer, A., Marhic, B., \& Delahoche, L. (2017, May). Smart Home, Smart HEMS, Smart heating: An overview of the latest products and trends. In 2017 6th International Conference on Systems and Control (ICSC) (pp. 90-95). IEEE.

[8] Kabilan, K., Bhalaji, N., Selvaraj, C., Mahesh, K. B., \& Karthikeyan, P. T. R.. Performance analysis of IoT protocol under different mobility models. Computers \& Electrical Engineering.

[9] Li, L. Y., \& Liu, C. D. (2015). An Improved Algorithm of LEACH Routing Protocol in Wireless Sensor Networks. International Conference on Future Generation Communication \& Networking.

[10] Rani, R., Kakkar, D., Kakkar, P., \& Raman, A. (2019). Distance-Based Enhanced Threshold Sensitive Stable Election Routing Protocol for Heterogeneous Wireless Sensor Network.

[11] Zhang, W. H., La-Yuan, L. I., Zhang, L. M., \& Wang, X. Z. (2008). Energy consumption balance improvement of leach of wsn. Chinese Journal of Sensors \& Actuators, 21(11), 1918-1922.

[12] Attea, BA, \& Khalil, EA (2012). A new evolutionary-based routing protocol for clustered heterogeneous wireless sensor networks. Applied Soft Computing Journal, 12 (7), 1950-1957.

[13] Ma, K., Zhang, Y. , \& Trappe, W.. (2008). Managing the mobility of a mobile sensor network using network dynamics. IEEE Transactions on Parallel and Distributed Systems, 19(1), 106-120.

[14] Yang Caixia, Koryo, Luchang. A Clustering Algorithm for Balancing Node Energy Consumption in WSN [J]. Journal of Jiamusi University (Natural Science Edition), 2015, 33 (6): 925-928.

[15] Du Chao. Analysis and Simulation of LEACH-C protocol based on NS2 [J]. Electronic measurement technology, 2011, 34 (9): 121-123.

[16] Kwiatkowska, M., Norman, G., Parker, D., \& Qu, H. (2010). Assumeguarantee verification for probabilistic systems. Lecture Notes in Computer Science, 6015, 23-37.

[17] Singh, C. P., Vyas, O. P., \& Tiwari, M. K. (2008). A Survey of Simulation in Sensor Networks. International Conference on Computational Intelligence for Modelling Control \& Automation.

[18] J. Zhu, R. Pecen. A novel automatic utility data collection system using IEEE 802.15.4-compliant wireless mesh network[C]. In proceedings of IAJC-IJME International Conference, 2008.

[19] [Aslam, M., Javaid, N., Rahim, A., Nazir, U., Bibi, A., \& Khan, ZA (2012). Survey of extended leach-based clustering routing protocols for wireless sensor networks.

[20] Murthy, S., \& Garcialunaaceves, JJ (1996). An efficient routing protocol for wireless networks. Mobile Networks \& Applications, 1 (2), 183-197.

[21] Rani, R., Kakkar, D., Kakkar, P., \& Raman, A. (2019). Distance-Based Enhanced Threshold Sensitive Stable Election Routing Protocol for Heterogeneous Wireless Sensor Network.

[22] Zheng, X., Ge, L., Guo, W., \& Liu, R. (2007). Cross-Layer Design and ant-colony optimization-based load-balancing routing protocol for adhoc networks. Frontiers of Electrical and Electronic Engineering in China, 2(2), 219-229.
[23] Ortolani, S., Conti, M., Crispo, B., \& Pietro, R. D. (2011). Events privacy in WSNs: A new model and its application. IEEE International Symposium on A World of Wireless.

[24] Wang, Q. H., Guo, H. Y., \& Ji, Y. H. (2011). Research and improvement of leach protocol for wireless sensor networks. Journal of Chongqing University of Posts \& Telecommunications, 562-564, 13041308.

[25] Yanchun, T. U., \& Guo, A. (2006). Routing algorithms and simulation of the wireless sensor network. Computer Engineering, 32(22), 124-126.

[26] Feng, Y., Kang, H. E., Yang, H., Qiu, Z., \& Liu, Y. (2014). The research and optimization of data gathering protocol for wireless sensor network. Chinese Journal of Sensors \& Actuators, 27(3), 355-360.

[27] Hüseyin Özgür Tan. (2003). Power-efficient data gathering and aggregation in wireless sensor networks. Acm Sigmod Record, 32(4), 66-71.

[28] Wu, X., \& Sheng, W. (2010). Performance Comparison of LEACH and LEACH-C Protocols by NS2. International Symposium on Distributed Computing \& Applications to Business.

[29] Thein, M. C. M., \& Thein, T. (2010, January). An energy-efficient cluster-head selection for wireless sensor networks. In 2010 International Conference on Intelligent Systems, Modelling, and Simulation (pp. 287-291). IEEE.

[30] Li Lanying, Liu Changdong. An improved LEACH algorithm for wireless sensor network routing protocol [J]. Journal of Harbin University of Technology, 2015, 20 (02): 75-79.

[31] Mankita, Singh, E. P., \& Rani, E. S. Improved leach routing communication protocol for wireless sensor network. International Journal of Distributed Sensor Networks, 2012, 1-6.

[32] Afsar, M. M., \& Tayaranin, M. (2014). Clustering in sensor networks: a literature survey. Journal of Network \& Computer Applications, 46, 198-226.

[33] Wang, Y. H., Yu, C. Y., Chen, W. T., \& Wang, C. X. (2008). An average energy-based routing protocol for Mobile Sink in wireless sensor networks. IEEE International Conference on Ubi-media Computing.

[34] Qin, Xianglin, H. Zhang, and Y. Zhang. "Research on wireless sensor networks clustering routing algorithm based on energy balance." International Conference on Measurement 2012.

[35] Sharma, N., Prakash Verma, C., \& Kumar Mahirania, R. (2014). Prototypedleach routing algorithm for the enhancement of energy efficiency in the wireless sensor network. International Journal of Computer Applications, 95(18), 30-32.

[36] Aslam, M., Javaid, N., Rahim, A., Nazir, U., Bibi, A., \& Khan, ZA (2012). Survey of Extended LEACH-Based Clustering Routing Protocols for Wireless Sensor Networks. IEEE International Conference On High-Performance Computing \& Communication \& IEEE International Conference on Embedded Software \& Systems.

[37] Bartolini, N., Massini, A., \& Silvestri, S. (2012). P\&p: an asynchronous and distributed protocol for mobile sensor deployment. Wireless Networks, 18(4), 381-399.

[38] Arya, R., \& Sharma, S. C. (2018). Energy optimization of, energy-aware routing protocol and bandwidth assessment for wireless sensor network. International Journal of System Assurance Engineering \& Management, 26(5), 1-8.

[39] Di, T., Li, T., Jian, R., \& Jie, W. (2015). Cost-aware secure routing (caser) protocol design for wireless sensor networks. Parallel \& Distributed Systems IEEE Transactions on, 26(4), 960-973.

[40] Al-Karaki, J. N., \& Gawanmeh, A. (2017). The optimal deployment, coverage, and connectivity problems in wireless sensor networks: revisited. IEEE Access, PP(99), 1-1.

[41] Babar Ali,Tariq Mahmood, Muhammad Abbas, Muzamil Hussain, Habeeb Ullah, Anupam Sarker, Asad Khan.(2019).LEACH Robust Routing Approach Applying Machine Learning.IJCSNS,.19(6),18-26. 